\title{
AIR TRANSPORTATION: PERCEPTION AND IMPACT OF PASSENGERS WITH REDUCED MOBILITY
}

Sara Zorro (corresponding author)

CERIS, Instituto Superior Técnico, Universidade de Lisboa, Av. Rovisco Pais 1, 1049-001, Lisboa, Portugal

Rosário Macário

CERIS, Instituto Superior Técnico, Universidade de Lisboa, Av. Rovisco Pais 1, 1049-001, Lisboa, Portugal C-MAT-TPR-Faculty of Business and Economics, University of Antwerp

Jorge Silva

Universidade da Beira Interior, Aerospace Sciences Department (UBI-DCA), Rua Marquês d'Ávila e Bolama, 6201001, Covilhã, Portugal

\begin{abstract}
Air transport has many restrictions for persons with reduced mobility (PRM). This study aims to better understand the needs of PRMs and the main constraints they face within airports and aircraft. The passengers' air rights and how they are being met for PRMs were analysed. An online survey was used to gather information about accessibility constraints and PRMs' perception of air travel. The specific regulations for these passengers are not being properly complied with. There is still room for both airports and airlines to improve PRM experience during air travel.
\end{abstract}

\section{KEYWORDS}

accessibility, persons with reduced mobility, passenger rights, airport barriers, aircraft barriers, PRM perception.

Sara Zorro (MSc), graduated in Aeronautical Engineering from the University of Beira Interior (UBI). Currently, she is a medical student at UBI. The areas of her scientific activity include Air Transport, Flight Safety and Accessibility. Email: sara.zorro@tecnico.ulisboa.pt

Rosário Macário, is a Professor and Researcher in Transportation at the Department of Civil Engineering, Architecture and Georresources at Instituto Superior Técnico (IST) Universidade de Lisboa and Guest Professor at University of Antwerp, Department of Transport and Regional Economics (Belgium). She is also Editor-in-Chief of the Elsevier journal "Case studies for Transport Policy". Email: rosariomacario@tecnico.ulisboa.pt

Jorge Silva has a Graduation in Marine Systems Engineering of Electronics and Telecommunications, an MSc in Operations Research and Systems Engineering, and a PhD in Transportation. He is also member of the American Institute of Aeronautics and Astronautics (AIAA). Email: jmiquel@ubi.pt 


\section{INTRODUCTION}

Air transport has many restrictions for PRMs. The difficulties in accessibility and all the logistics required for PRMs to get around the airport and board an aircraft is more than a few. The increasing demand for reduced mobility services is becoming a major challenge for both airports and airlines in terms of human and material resources, and operational logistics. Therefore, new strategies need to be adopted to ensure that PRMs can enjoy the air travel experience like any other passengers.

Besides the slight evolution in some airport infrastructure and services regarding this subject, the overall objective of this research is the improvement of the accessibility of air transport. For this, we must first address the main obstacles inherent to air transport. As such, this paper aims to better understand the needs of PRMs and the main constraints they face within airports and aircraft. It will first focus on thoroughly researching the passengers' air rights and how they are being met for PRMs. Then go on to finding out the main constraints that PRMs face within airports and aircraft. Therefore, to understand the poor accessibility and PRMs' perception of air travel we prepared a survey instrument in the form of an online questionnaire. Finally, the results are analysed and discussed.

\section{LITERATURE REVIEW}

About 80 million Europe citizens currently suffer from mobility impairments (European Commission, 2010), and by 2050 the European population aged 65 and over is expected to reach $25.1 \%$ (OECD, 2015). Around the world there are about 900 million people aged 60 years and over, of whom 125 million are more than 79 years old (United Nations, 2014). This means that in a few years the percentage of the population with reduced mobility (children, pregnant women, people with disabilities, older persons, the obese, etc.) will be even more significant and an urgent but wise investment by airlines and airports industry is therefore justified.

According to the World Health Organization (WHO), approximately $15 \%$ of the population lives with some type of disability - 20\% in developed countries and $80 \%$ in developing countries (World Health Organization, 2011). Due to the "(...) greater vulnerability of modern daily life to various dangers such as industrial and natural disasters, diseases, traffic accidents, addiction to drugs and/or alcohol, violence, and pollution, combined with (...)" (Lee, Agarwal, \& Kim, 2012) population growth, medical advances and aging process the percentage of disabled population is expected to increase. 
The increasing reduced mobility population also offers opportunities, such as new developments in technology and innovation; and market approaches to retrofit existing infrastructures and vehicles allowing PRM to maintain or regain their autonomy. More autonomy for PRM can also be seen as the result of socio-economic conditions that make it possible to live inclusively and more productive lives, and as something that provides opportunities for growth (OECD, 2015).

A reduced mobility society intensifies the need to address inequality, which compromises socio-economic resilience. Transportation policies can have a key role in empowering PRM and building resilience in the economy and societies.

\subsection{Passenger Rights}

In 2006, the United Nations adopted the International Convention about the Rights of Persons with Disabilities that expressly prohibits all forms of discrimination based on disability. Discrimination by any form - attitudinal, behavioural and/or institutional - violates the human rights. Participation in society is a right of all human beings. Thus, the definition and implementation of strategies and policies to minimize the physical and attitudinal barriers is a responsibility of the entire community (Jonh \& Rajé, 2007). As a worldwide mode of transportation, airlines must respect and follow the regulations in force in the operation countries - bilateral agreements.

In the European Union (EU), Regulation (EC) No. 1107/2006 reinforces the rights of passengers with disabilities and reduced mobility on air transport. It states that in the EU all the airports should be comparable in mobility in terms of accessibility to these passengers. PRM must have the same opportunities for air travel as the other citizens. As such, "(...) assistance to meet their particular needs should be provided at the airport as well as on board aircraft, by employing the necessary staff and equipment. In the interests of social inclusion, the persons concerned should receive this assistance without additional charge."(The European Parliament and the Council of Union European, 2006). The measures proposed in regulation No. 1107/2006 are considered by the European Commission of Transport as an effectively response to the needs of a growing sector of the population. Yet, it admits that the transport of PRM can be denied for justified reasons as security.

The Air Carrier Access Acct (ACAA) of the US demands that all the US and foreign airlines that fly to and from the US must have aircraft with accessible services for PRM. The ACAA applies to all flights to and from the US, and also prohibits the discrimination and denial of transportation of these passengers by the airlines. (Air Carrier Access Act (ACAA, 49 U.S.C. 41705), 1986). The Department of Transportation (DOT), in interpreting and implementing 
the ACAA - Regulation 14 CFR Part 382 -, defined a rule with standard services that airports and airlines are expected to provide to PRM; for example, airport and airlines employees should be fully prepared and trained to assist PRM within the airport and the aircraft, and both lavatories, in the airport and in the aircraft, should be fully accessible to PRM, and equipped with grab bars and extensible wide doors (U.S Department of Transportation, 2003), (FAA, 2015). However, these recommendations are not fully followed by airports and airlines. Regulation 14 CFR Part 382 maintains that an airline can legally require to a disabled passenger that needs physical help to travel with a safety assistant. The boarding/deplaning assistance should be provided considering the passenger safety and needs, and using adequate and prepared attendants and equipment (U.S Department of Transportation, 2003). The Air Travel Consumer Report of the US Department of Transportation revealed that the disability complaints are up, approximately, 14 per cent year on year (Castiglioni, 2015). European countries have no legal obligation to record complaints; however, the European Commission revealed that complaints related to travel disability were up to $148 \%$ in 2012 , expecting to increase in the next years. Two of the largest airports in the EU receive more than 100 complaints related to PRM rights per month. This situation reveals that the Regulation (EC) $1107 / 2006$ is not being applied as it should. Therefore, complaints register by airports and airlines should become obligatory in the EU countries and immediate actions should take place to monitor and ensure these passengers rights according to the current regulation (Castiglioni, 2014). However, the report from the Commission to the European Parliament and the Council "(...) concluded that Regulation (EC) No 1107/2006 has brought advantages to disabled persons and persons with reduced mobility (PRM); (...)", (European Commission, 2011). Some difficulties in applying the regulation were also indicated, namely:

- Insufficient quality of service provided and inadequate adaption to PRM's individual needs;

- Insufficient in-flight assistance by the air carriers, particularly in moving to toilet facilities;

- Disparities in the implementation of the regulation between EU countries.

Therefore, to improve the existing framework the interpretation of the regulation must be uniformed; improve how the regulatory instruments work in practice; strengthen the efficacy of the penalties ant its supervision by national authorities; and make obligatory in the EU countries the register of passengers complaints by airports and airlines(European Commission, 2011), (Castiglioni, 2014), (European Commission, 2011).

In summary, all the mentioned regulations, directly or indirectly, require private and public agencies to implement reasonable actions to improve the social inclusion of disabled people. In result, some progressive change has been noticed in social attitude towards disability; the 
society "(...) focuses less on disability per se as a factor which determines full participation in all aspects of life, and more upon the constraints imposed by society as a whole."(Lee et al., 2012).

\subsection{Accessibility Constraints}

Personality, lifestyle, socio-economic and cultural characteristics are the main common factors that influence everyone's decision when choosing a transportation mode. For PRM, the accessibility is the most important factor to consider when planning a trip. Being aware about these passengers needs and having the ability to communicate with them effectively is an important step to overcome physical and psychological barriers. People involved in the design, management and special services provision need to be aware and understand the mobility impairment concept, to develop accessible infrastructures and, consequently, ensure that persons with reduced mobility will be able to move along the airport like any other nondisabled passenger.

Disabled travelers present significantly different travel experiences, and air transportation industry is pointed as a possible responsible since it has not yet fully responded to the PRM needs. Passengers with different impairment levels have different perceptions about importance and satisfaction of barrier-free accessibility. The seat arrangement and lavatories on the aircraft are considered by the disabled passengers the least satisfactory attributes ( $Y$. C. Chang \& Chen, 2011).

Depending on nature and the severity of the disability, people refer different fears and risk levels. For instance, passengers with visual impairments feel vulnerable in new and unfamiliar environments and fear for their safety; and spinal cord injuries passengers are concerned about the urinary control and the possibility of airlines losing their "legs" (wheelchair) (Yau, McKercher, \& Packer, 2004).

Lack of disability awareness training and attitudinal barriers are also an important issue. Attitudes of airport and airlines staff can be changed. Repeated exposure and practical knowledge about disabled persons would enhance knowledge and behaviors of service personnel with such individuals. Operators and service providers need to embrace a more holistic perception about the importance of attitudinal modification to provide a good travel experience for all passengers equally. The internalization of a more positive attitude towards PRM would improve the social inclusion and, consequently, all civil society (Daruwalla \& Darcy, 2005). 


\subsubsection{Airport Barriers}

Several factors inhibit PRM from using airport infrastructures; such as, the environment itself, including the attitudinal, architectural and ecological barriers; interactive and communication barriers; and intrinsic barriers that represent the greatest obstacle since they depend on the physical, psychological or/and cognitive functioning of each person (McKercher, Packer, Yau, \& Lam, 2003).

Cultural and social attitudes about PRM - quite different among countries and people represent one of the most difficult obstacles to overcome. Negative and discriminatory attitudes can influence and change someone's perception of himself/herself as a person with equal rights to live in society (Yau et al., 2004). The main items regarding the PRM's satisfaction in air transport are the attitudinal behaviour of the airport/airlines staff during the embarking and disembarking phases, and at the check-in counters (Y. C. Chang \& Chen, 2011).

Important travel information for PRM is on airports and airlines websites; however, specialized services and regulations are different between them. A flight reservation for a PRM can be quite time and patience consuming, and sometimes the lack of information obligates the passenger to physically go to the airport to buy the ticket (Y.-C. Chang \& Chen, 2012).

Elderly, a particular part of the PRM population, are often not familiar with the airport facilities when they book a flight. Their ability to understand, read and listen the information and instructions given at the airport is hampered by the lack of vision and hearing, as well as the decreased cognitive abilities. Therefore, airports should also provide clear and easy to understand information about emergency exits, directions at the airport terminal, and transport means to get in and out of the airport. The importance of special services provided by airlines and airports increases with increasing age of the passenger.

Passengers with reduced mobility are usually slower and unstable; as such, one of the main priorities is to assure the full airport floor conditions to prevent falls. Ramps and elevators accesses and respective support equipment (wheelchairs) must always be unimpeded and available for use (Y. C. Chang \& Chen, 2011).

The wheelchair transport is also a common problem reported by disabled passengers. Airport operators and air carriers receive several complaints about damaged wheelchairs, delays in baggage claiming or even about wheelchairs that don't arrive at all (Lee et al., 2012). Restaurants, shops, restrooms, bathrooms and lounges totally accessible are also difficult to find at the gate areas in airports (Y.-C. C. Chang \& Chen, 2012). 
Besides all the physical barriers, PRM also have to be prepared to deal with unexpected situations. A common delay or flight cancellation can be a huge discomfort for all passengers but especially for passengers with disabilities whose resistance to deal with unpredictable situations is limited (Ray \& Ryder, 2003).

All the mentioned factors have a dissuasive effect on PRM. The travel experience is essential to make the passenger, being him/her abled or disabled, wish to travel again. Therefore, airport and aircraft accessibility barriers need to be eliminated to improve passenger's willingness to fly and, consequently, increase the number of passengers with reduced mobility (Sara, Rosário, \& Jorge, 2015).

\subsubsection{Air-Ground Interface Barriers}

The physical transfers and the lack of specialized and trained personal are important alienating factors. For PRMs, the obstacles are many, with additional devices being needed for boarding and disembarking; standard wheelchairs, rollers, strollers are too wide to fit the aircraft aisle; and the aircraft lavatories are too small even for an adapted wheelchair. However, in terms of aircraft cabin configuration, hardly any devices or solutions have been applied, improved or re-designed in decades.

Different types of disability require different stages of transference. Usually, a disabled passenger is transferred from on seat or device to another at least four times during a flight trip. The whole transference process involves four types of devices, typically provided by the airport or the airline carrier:

- Standard airport wheelchairs;

- Boarding or aisle chairs;

- Standard aircraft seat;

- Wheelchair for mobility within the aircraft.

Due to lack of comfort and functionality, especially for passengers with severe conditioned mobility, the aisle chair or boarding chair is one of the most feared devices within the travel experience.

For boarding and deplaning of PRM, the standard procedures demand the assistance of at least two specialized attendants. However, the physical transfers present some liability issues once in some cases the attending personal are not adequately prepared for this situations, "International passenger-service workers (...) $60 \%$ said they had not been formally trained in how to lift an immobile passenger."(Lollis, 2008). Besides, the physical contact between the passenger and the helpers during the transfers to and within the aircraft has also to be authorized. According to worldwide regulations, airlines must provide special services for PRM; 
and on the ground, there must be specialized passenger attendants prepared for ground physical assistance and transfers. Besides assistance within the cabin - in moving to and from seats, in preparation for eating, with the use of the on-board wheelchair to enable the person to move to and from a lavatory (not involving lifting or carrying the person) and in loading and retrieving carry-on items - be also required, airlines are not required to provide extensive special assistance in personal services as assistance within the lavatories (U.S Department of Transportation, 2003).

Injuries during the physical transfer process are a major concern; several occurrences have been reported during dependent transfers between a wheelchair/boarding chair and aircraft seat (U.S Department of Transportation, 2015). These transfers usually require two persons, one to hold the arms and the other hold beneath the passenger knees; together the transferors lift the passenger and shift him to the respective seat (Pelosi, 1988). This method puts both the passenger and the attendant personal at risk of injuries from being roughly handed or dropped and of a disabling back injury, respectively (Higginson, Welsh, \& Pavol, 2007).

\subsubsection{Aircraft Barriers}

Airlines face a growing number of passengers that can't walk, and, therefore, presumably a growing number of complaints as a result of the compensation economy. Currently, there are around 100 complaints about seating and around 50 inquiries about special needs a year in the UK (Aircraft Interiors International, 2014). However, nowadays few solutions have been employed to improve the accommodation of these passengers. Boarding and disembarking phases are preoccupant issues, both physically and emotionally, as well as the seats, seatbelts, tray tables, lavatories, aisles and overhead storage compartments. All these factors result in an unpleasant flight experience.

According with Regulation 14 CFR Part 382, new aircraft with 30 or more seats must have movable aisle armrests on half the aisle seats; airlines are required to allocate accessible lavatories only on aircraft with more than one aisle; new aircraft with 100 or more seats must have priority space for storing a passenger's folding wheelchair in the cabin; and aircraft with more than 60 seats and an accessible lavatory must have an on-board wheelchair (U.S Department of Transportation, 2003). Unfortunately, in EU it is not part of the Regulation (EC) No. 1107/2006 the obligation of having accessible lavatories regarding the type of aircraft; and how the airlines should implement the assistance in moving passengers to toilet facilities - it is only claimed that "Assistance in moving to toilet facilities is required." (The European Parliament and the Council of Union European, 2006). 
Due to the lack of uniformed worldwide regulations, several travel guides for PRM recommend wearing diapers, since some aircraft might not have accessible lavatories or on-board wheelchairs, and, in case they have, the transfer process into the toilet can be both problematic and discomforting. In some situations, the on-board wheelchair is not able to carry the passenger, or it doesn't fit into the lavatory. In those cases, assistance is required during the transfers. As such, PRM are often assigned middle seats away from any lavatory as a mean to dissuade them to use it, ask for assistance and/or disturb the other passengers (Law F., 2012).

\section{CONTRIBUTIONS}

This study aims to better understand the needs of PRMs and the main constraints they face within airports and aircraft. Therefore, an online survey was used to gather reliable information about accessibility constraints and PRMs' perception of air travel.

\subsection{Survey Design and Data Collection}

A survey instrument in the form of an online questionnaire to collect PRMs' perception of the accessibility of air transport was prepared. The 25 items used were defined based on the literature review, and include the respondent's personal and demographic characteristics, as well as travel-related characteristics. An email was sent to several national institutions, explaining the purpose of the study and asking about their willingness to take part in the survey. The link to the enquiry was included in the email. The survey was delivered via an open source web-based platform (Google Forms) ${ }^{1}$, and it has been online since July 2015.

\subsection{Results}

The results obtained have undergone a first analysis and interpretation. The target population of this study was people with disabilities and people who have accompanied PRMs on an air trip. Of the valid 119 responses collected, only 50 mentioned any type of reduced mobility. For analysis purposes only this group of respondents was considered, since the objective of the study is the PRMs' perception of air travel. The statistical analysis was performed using SPSS Statistics $23 \AA$ for Microsoft Windows $₫$.

1 https://docs.google.com/forms/d/1yP6t3U3GAgk3LpJTbz8oLfX8Z1LE8chy XB5PWEG3UI/viewform 


\subsubsection{Socio-demographic profile of respondents}

The results showed that with respect to the socio-demographic profile of the PRM respondents males predominated in the sample, 33 to 17 . Mean age was $43.3 \mathrm{yrs}$ ( $\mathrm{min}=14 \mathrm{yrs}$, $\max =85$ yrs, $S D=18.4)$. Concerning the disabilities suffered by the respondents, most were mobilityimpaired (77\%), followed by those with sensory (15\%) disabilities. About $4 \%$ mentioned both cognitive and mobility impairments, and $4 \%$ referred both sensory and mobility difficulties (Figure 1).

\section{Figure 1 - Type of disability exhibited by the sample}

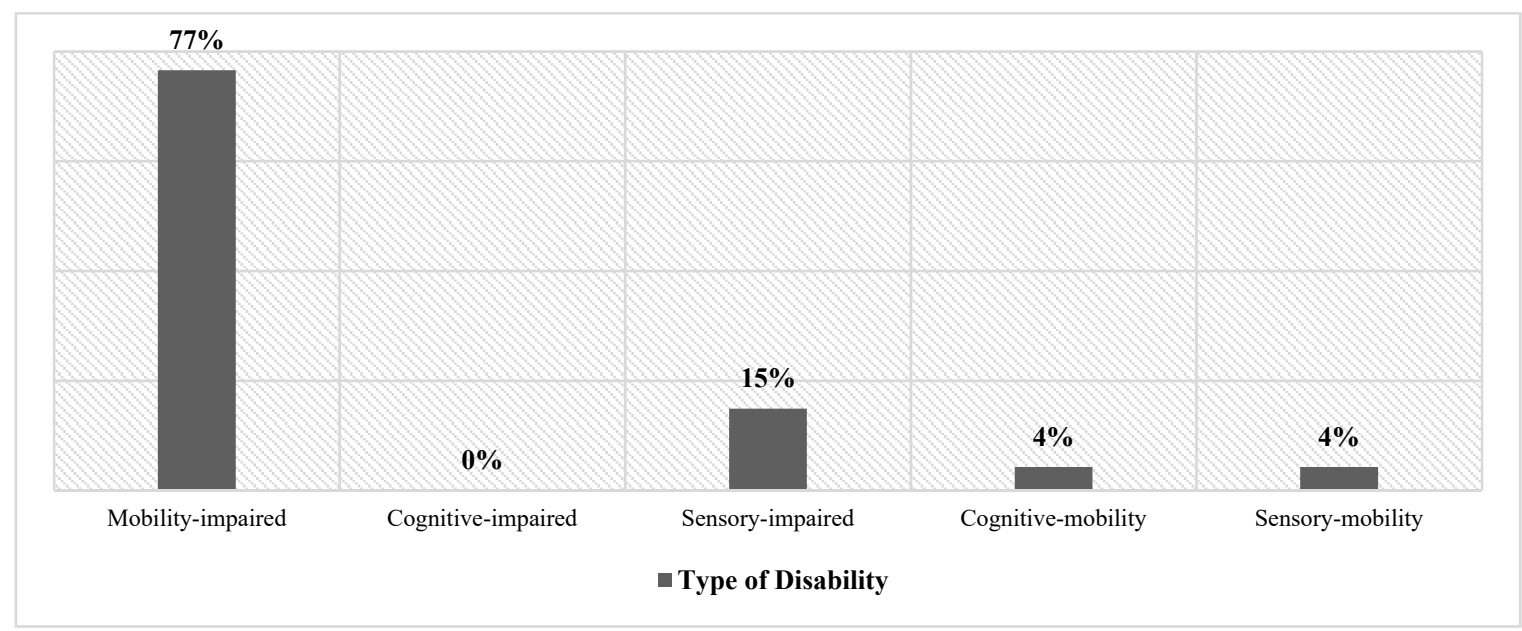

\subsubsection{PRM Perception about Air Transportation}

$27 \%$ of the sample reported that had already given up of flying due to a bad experience. It is also clear that an improvement in the quality of the assistance service provided could attract more PRMs to air transport (59\%) (Figure 2).

Figure 2 - Percentage of responses about the flight experience and the quality of the service provided

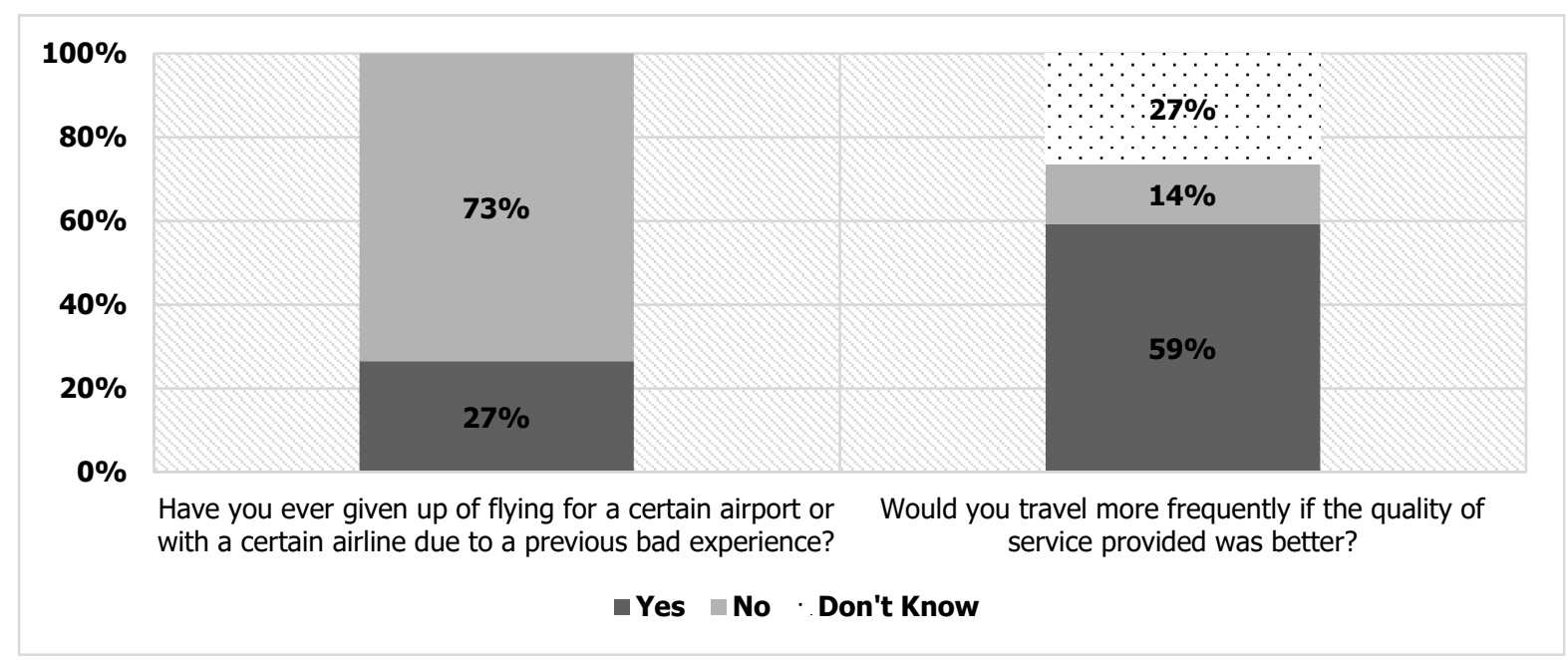


$48 \%$ believe that air transport isn't an easy mode of transportation. However, $22 \%$ didn't have an opinion about it. The respondents were also clear about the difficulties in getting information about PRM assistance services (60\%), and even more expressive about the need for mandatory regulation (80\%) (Figure 3).

\section{Figure 3 - Respondents perception about accessibility, information and regulation of air transport}

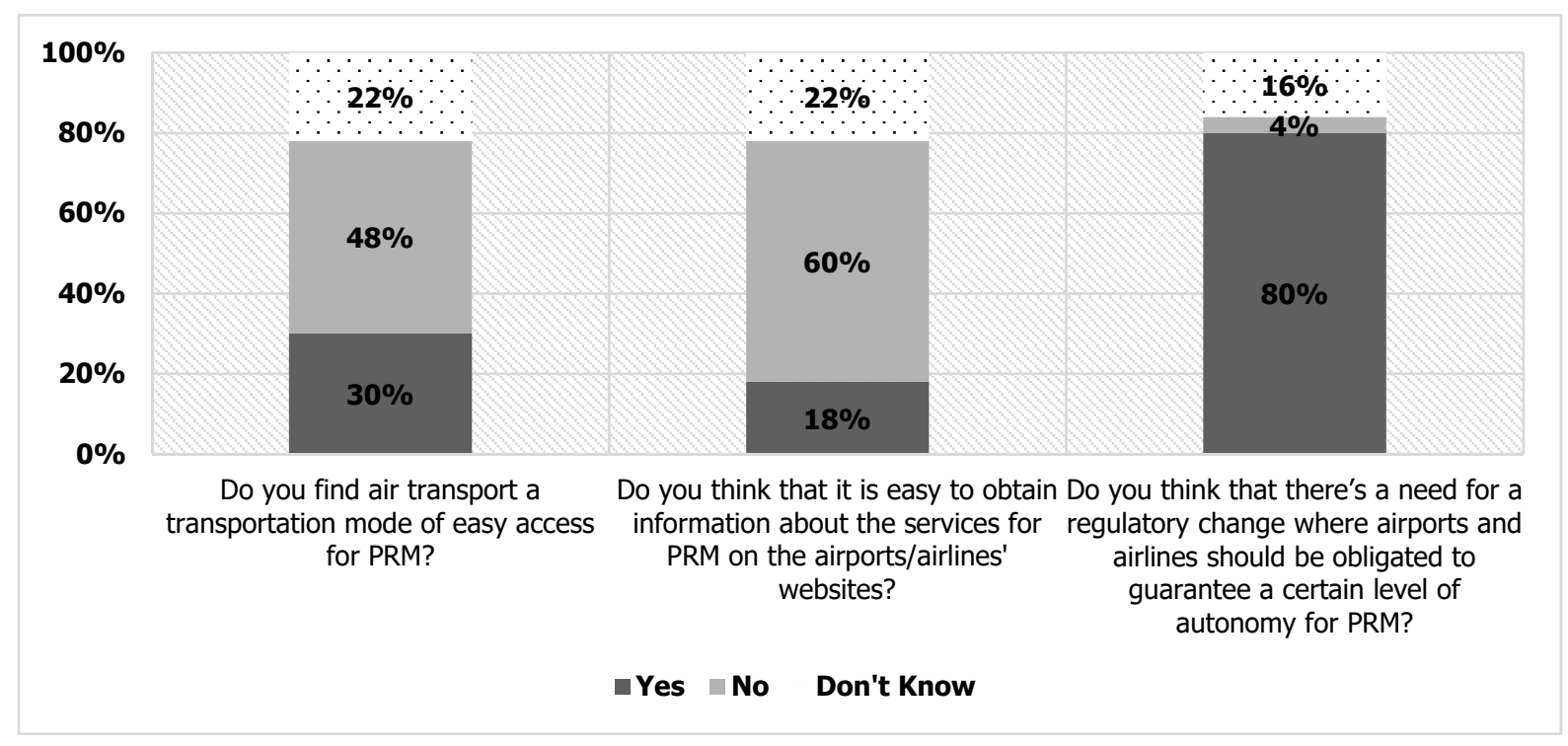

\subsubsection{Airport Constraints}

Regarding airport constraints, it is clear that the baggage claim (45\%), the lack of specialized and trained personal (44\%) and the transfers at the airport terminal (39\%) are very important barriers for these passengers. Information about the emergency exits is another subject that clearly preoccupies PRMs (36\%). The less important issues, identified as somewhat important and not at all important, were the lavatories (43\%) and the waiting areas (40\%) (Figure 4).

\subsubsection{Aircraft constraints}

Regarding the aircraft constraints, the lavatories (51\%), the space between seats (43\%), the seat transfers (41\%), the boarding/disembarking transfers (37\%), and the mobility inside the aircraft (32\%) were considered as very important obstacles. The less important issues, identified as somewhat important and not at all important, were the seat-belt (66\%) and the accommodation of the carry-on baggage (48\%) (Figure 5). 
Figure 4 - Importance scale of the different airport constraints

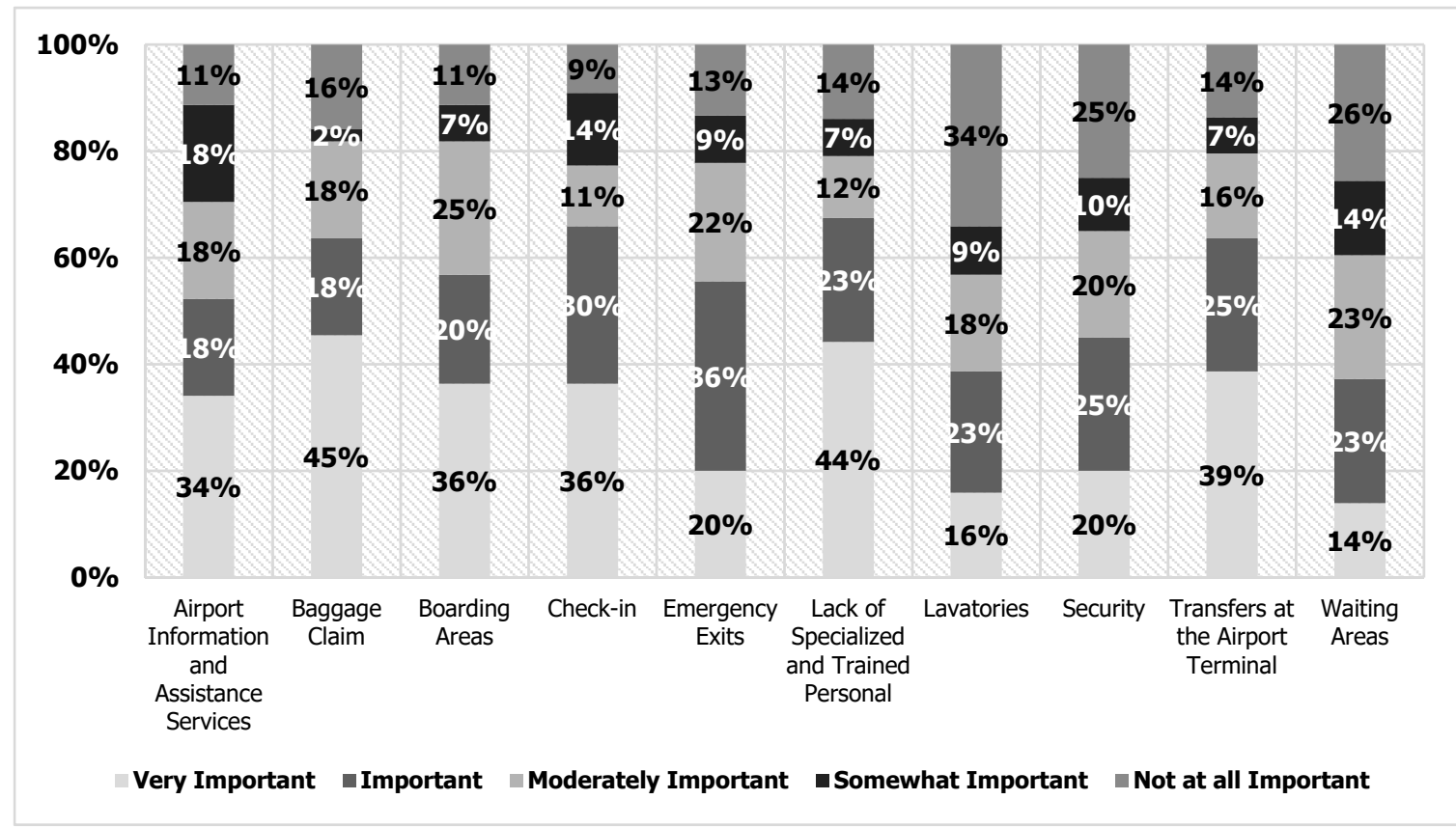

Figure 5 - Importance scale of the different aircraft constraints

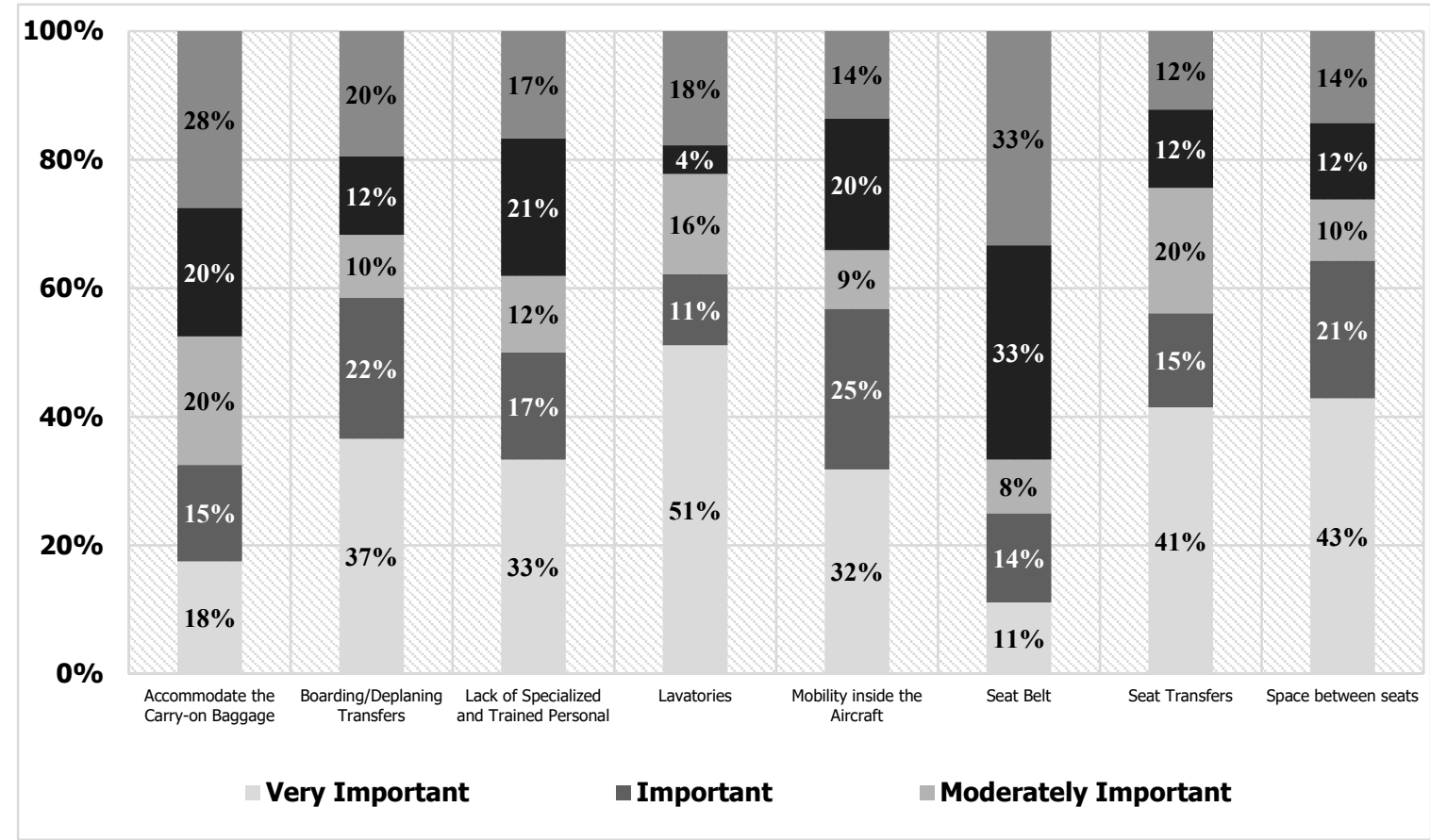

\subsection{Discussion}

Mobility impairments are the most common disabilities suffered by PRMs (77\%), and this may be why $27 \%$ of the sample reported that had already given up of flying due to a bad experience. It is also clear that an improvement in the quality of the assistance service provided could attract more PRMs to air transport (59\%). However, a certain uncertainty can be seen, since $27 \%$ were not sure if those improvements would make them travel more. 
When questioned about the accessibility of air transport, a large proportion of the respondents answered No (48\%), which leads us to believe that there is still room for improvement.

The respondents were also clear about the difficulties in getting information about PRM assistance services (60\%), and even more expressive about the need for mandatory regulation (80\%). This proves that these passengers feel excluded and encounter some difficulties in finding out about their rights amid the airport/airline's world of information. It is a fact that there are specific regulations for these passengers, but are they being properly complied with? Well, these results show that in this sample's perception they are not, or at least it does not feel that they are.

Regarding airport constraints, the lack of specialized and trained personal (67\%), the checkin $(66 \%)$, the transfers at the airport terminal (64\%), the baggage claim (63\%), the boarding areas (56\%) and the emergency exits (56\%) are important barriers for these passengers. Therefore, these issues could be a focus area for airports to improve PRM experience during air travel.

Regarding aircraft constraints, the most problematic issues were deemed to be the space between seats $(64 \%)$, the lavatories (62\%), boarding/deplaning transfers (59\%), mobility inside the aircraft (57\%) and seat transfers (56\%). Airlines must invest in more comfortable seats (economy class) and ways of transferring a PRM into and within the aircraft. Several solutions have been developed to minimize physical transfers, however, very few have been applied, although, some aircraft models have already implemented more spacious lavatories.

\section{CONCLUSION}

Persons with reduced mobility comprise a passenger category that is increasing in air transport. Therefore, airports and airlines need to improve their strategies to better serve all types of passengers. This must happen not just because of equal rights but also because reduced mobility is something that in the short or long run will affect almost every single person. A full and complete perception of this imminent reality is therefore both urgent and necessary to better cope with the upcoming issues, where both airports/airlines and passengers can be the beneficiaries.

We argue that analysing PRMs' perception of air transport barriers will allow us to better tackle the issues regarding accessibility. Therefore, we need to identify the main issues regarding PRM services and its influence on accessibility and operations logistics. Then, propose solutions to minimize those barriers; and alert airports/airlines to the existent problems and help them find ways to better manage the PRM needs. 
It is our belief that to overcome the current and future issues airports and airlines need to adopt strategies that are cross-cut all stages of the chain of processes, from the moment the passenger arrives at the airport until the moment he/she is seated in the aircraft. Thus, solutions that work on both constraints and operational logistics optimization are believed to be the best future strategy for airports and airlines.

\section{REFERENCES}

- Air Carrier Access Act (ACAA, 49 U.S.C. 41705) (1986). Retrieved from https://www.law.cornell.edu/uscode/pdf/uscode49/lii_usc_TI_49_ST_VII_PA_A_30_ii_CH 417_SC_I_SE_41705.pdf

- Aircraft Interiors International. (2014). Articles : Aircraft Interiors International. Retrieved February $1, \quad 2015, \quad$ from http://www.aircraftinteriorsinternational.com/articles.php?ArticleID $=484$

- Castiglioni, R. (2014). Air Travel Disability Complaints Up 148\% in 2012 European Commission Data Shows. Retrieved February 14, 2015, from http://www.reducedmobility.eu/20140414446/The-News/air-travel-disability-complaintsup-148-in-2012-european-commission-data-shows.html

- Castiglioni, R. (2015). US air travel disability complaints up year on year. Retrieved February 14, 2015, from http://www.reducedmobility.eu/20150211590/The-News/us-airtravel-disability-complaints-up-year-on-year.html

- Chang, Y.-C. C., \& Chen, C.-F. F. (2012). Overseas travel choice for persons with reduced mobility. Journal of Air Transport Management, 20, 43-45. http://doi.org/10.1016/j.jairtraman.2011.11.005

- Chang, Y.-C., \& Chen, C.-F. (2012). Meeting the needs of disabled air passengers: Factors that facilitate help from airlines and airports. Tourism Management, 33(3), 529-536. http://doi.org/10.1016/j.tourman.2011.06.002

- Chang, Y. C., \& Chen, C. F. (2011). Identifying mobility service needs for disabled air passengers. Tourism Management, 32(5), 1214-1217. http://doi.org/10.1016/j.tourman.2010.11.001

- Daruwalla, P., \& Darcy, S. (2005). Personal and societal attitudes to disability. Annals of Tourism Research, 32(3), 549-570. http://doi.org/10.1016/j.annals.2004.10.008

- European Commission. (2010). European Disability Strategy 2010-2020: A Renewed Commitment to a Barrier-Free Europe. Retrieved from http://eurlex.europa.eu/LexUriServ/LexUriServ.do?uri=CELEX:52010DC0636:en:NOT\#top

- European Commission. (2011). Rights of people with reduced mobility in air transport. Retrieved February 14, 2015, from http://europa.eu/legislation_summaries/transport/air_transport/I24132_en.htm

- FAA. eCFR - Code of Federal Regulations, Title 14, Chapter II, Subchapter D, Part 382, Subpart E, 382.63 (2015). Retrieved from http://www.ecfr.gov/cgi-bin/textidx?SID=32bdaf398c275fd4ce21d6b5174b8b4a\&node=se14.4.382_163\&rgn=div8

- Higginson, B., Welsh, L., \& Pavol, M. (2007). RISK FACTORS FOR INJURY DURING DEPENDENT TRANSFERS ON AN AIRCRAFT. TRANSED 2007. Retrieved from http://www.transedconferences.com/Transed2007/pages/1265.htm

- Jonh, F. P., \& Rajé. (2007). Accessibility, mobility and transport-related social exclusion. Journal of Transport Geography, 15(3), 151-160.

- Law F., S. (2012, April 10). System and Method for Integrating Handicapped Accessible Seats into Aircraft Interior Configurations. United States of America: Google Patents. Retrieved from https://www.google.com/patents/US8152101

- Lee, B. K., Agarwal, S., \& Kim, H. J. (2012). Influences of travel constraints on the people with disabilities' intention to travel: An application of Seligman's helplessness theory. Tourism Management, 33(3), 569-579. http://doi.org/10.1016/j.tourman.2011.06.011

- Lollis, B. De. (2008). Airlines tackle wheelchair need. Retrieved February 14, 2015, from http://usatoday30.usatoday.com/travel/flights/2008-03-12-wheelchair-travel_N.htm

- McKercher, B., Packer, T., Yau, M. K., \& Lam, P. (2003). Travel agents as facilitators or inhibitors of travel: Perceptions of people with disabilities. Tourism Management, 24(4), 465-474. http://doi.org/10.1016/S0261-5177(02)00107-3

- OECD. (2015). Ageing in Cities. Paris: OECD Publishing. Retrieved from 
http://dx.doi.org/10.1787/9789264231160-en

- Pelosi, T. M. G. (1988). Illustrated transfer techniques for disabled people. Melbourne: Churchill Livingstone.

- Ray, N. M., \& Ryder, M. E. (2003). "Ebilities" tourism: An exploratory discussion of the travel needs and motivations of the mobility-disabled. Tourism Management, 24(1), 5772. http://doi.org/10.1016/S0261-5177(02)00037-7

- Sara, Z., Rosário, M., \& Jorge, S. (2015). ACCESSIBILITY CONSTRAINTS IN THE AIRPORTAIRCRAFT. In TRANSED Conference.

- The European Parliament and the Council of Union European. REGULATION (EC) No 1107/2006 OF THE EUROPEAN PARLIAMENT AND OF THE COUNCIL of 5 July 2006 (2006). Retrieved from http://eur-lex.europa.eu/legal-content/EN/TXT/?uri=celex:32006R1107

- U.S Department of Transportation. 14 CFR Part 382 Nondiscrimination on the Basis of Disability in Air Travel (2003). Retrieved from http://airconsumer.dot.gov/rules/382short.pdf

- U.S Department of Transportation. Air Travel Consumer Reports (2015). Retrieved from http://www.dot.gov/airconsumer/air-travel-consumer-reports

- United Nations. (2014). Population ageing and sustainable development. Retrieved from http://www.un.org/en/development/desa/population/publications/pdf/popfacts/PopFacts 2014-4.pdf

- World Health Organization. (2011). World report on disability. The Lancet (Vol. 377). Retrieved from file:///C:/Users/Sara Zorro/Downloads/9789240685215_eng.pdf

- Yau, M. K. S., McKercher, B., \& Packer, T. L. (2004). Traveling with a disability - More than an Access Issue. Annals of Tourism Research, 31(4), 946-960. http://doi.org/10.1016/j.annals.2004.03.007 